\title{
63. Studies on the Karyotype Differentiation of the Norway Rat. II
}

A Mosaic Rat Carrying the Translocation and Inversion

of Pair No. 1 Chromosomes with a Note

on their Transmission to Offspring*)

\author{
By Tosihide H. YosidA \\ National Institute of Genetics, Misima \\ (Communicated by Sajiro Makino, M. J. A., June 12, 1980)
}

Some accounts on the $1 / 12$ chromosome translocation in a female Lewis strain rat were previously reported (Yosida 1980a). The no. 1 chromosome of the rat was heteromorphic for the translocation and its normal partner. The no. 12 of this rat was also heteromorphic for a normal element and a smaller partner by deletion (Fig. 4A). In 17 offspring obtained between the translocation rat and a normal male, 9 rats were homomorphic for the normal pair nos. 1 and 12, leaving 8 which were heteromorphic in pairs 1 and 12 for the translocation and deletion. One of the latter rats was mosaic consisting of two kinds of karyotype: One was heteromorphic for pair no. 1 consisting of the 1/12 translocation and normal partner, while the other showed the heteromorphic pair no. 1 resulted from $1 / 12$ translocation and the inversion partner.

The present paper describes the chromosome inversion of the pair no. 1 in some detail, with special reference to the distribution of the two cell types in the tissue of the mosaic rat, and the transmission of the normal, the translocation and inversion chromosomes no. 1 from the mosaic rat to its offspring.

Materials and methods. The origin of Lewis strain rats (Rattus norvegicus) used for study was the same as that described previously (Yosida 1980a). The Long-Evans strain rats were originally obtained from the Pacific Farm (U.S.A.) in 1956 and then they have been maintained by us by brother-sister mating for 60 generations.

The chromosomes were investigated in primary cultured cells from tail and ear tissues by our routine technique (Yosida 1980b). Bone marrow chromosomes were also subjected to study. The trypsin G-banding technique was applied.

*) Contribution no. 1319 from the National Institute of Genetics, Japan. Supported by a grant-in-aid for the scientific research from the Ministry of Education, Science and Culture. 
Results. 1) Occurrence of a female rat with chromosome mosaic. A female with heteromorphic pair no. 1 consisting of the $1 / 12$ translocation and the normal partner $(t /+)$ was crossed to a normal male rat with regular chromosome no. $1(+/+)$. From 3 litters 17 offspring were obtained. All of them had 42 chromosomes. In the 17 offspring, 8 rats (5우:3今) showed the pair no. 1 which was heteromorphic for the translocation and the normal partner (Fig. 4A). Among them one female was exceptional by showing the chromosome mosaicism having two different karyotypes. One showed heteromorphic pair no. 1 as described above, but the other one was remarkable by heteromorphic pair no. 1 involving the $1 / 12$ translocation and inversion partner (t/i) (Figs. 1, 2 and 4B). The inversion pair no. 1 chromosome was characterized by the submedian centromere. In
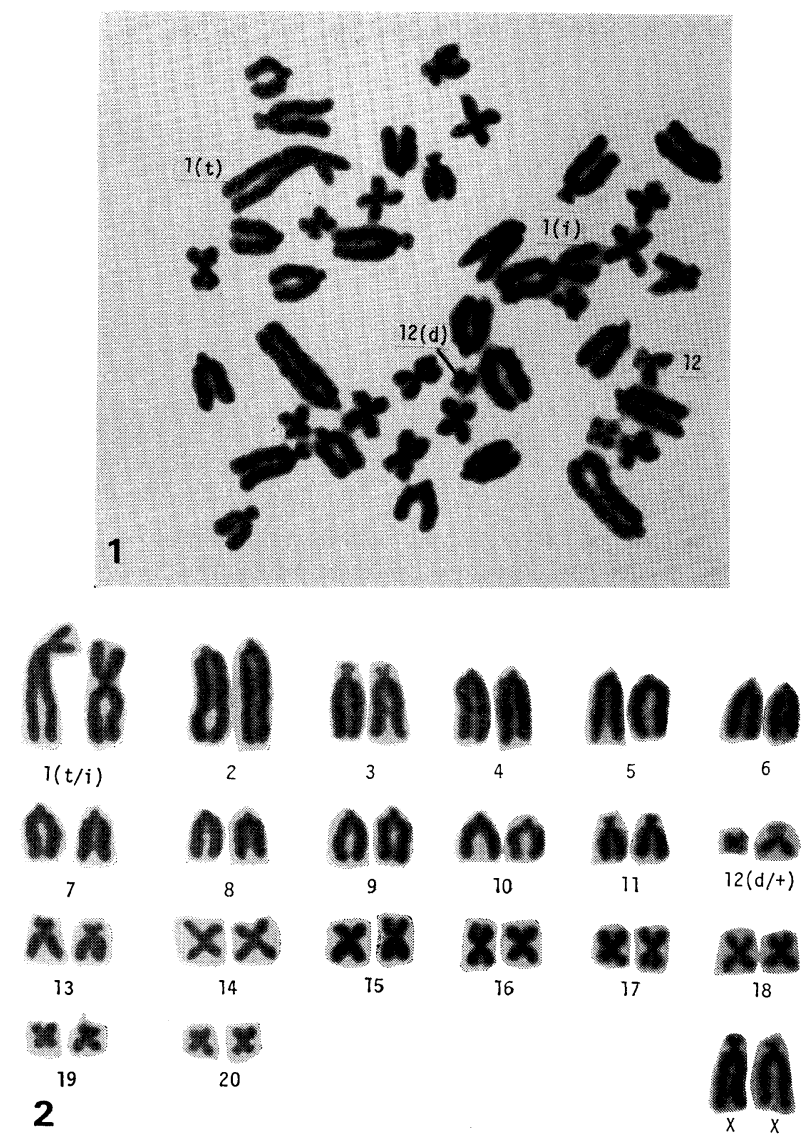

Figs. 1-2. A cell with the heteromorphic pair no. 1 for translocation and inversion found in a mosaic rat. 1(t) and 1(i) show translocation and inversion pair no. 1. 1: Metaphase. 2: Karyotype. Pair no. 12 is heteromorphic for deletion and normal $(d /+)$. 
total length, the inversion chromosome was similar to the normal no. 1 chromosome. This means that the submetacentric member might have produced by pericentric inversion of the normal chromosome which was a partner of the translocation pair no. 1. This is schematically shown in Fig. 3. By G-banding staining it could clearly be demonstrated that the submetacentric might have derived from the pericentric inversion of the normal pair no. 1 (Fig. 4).

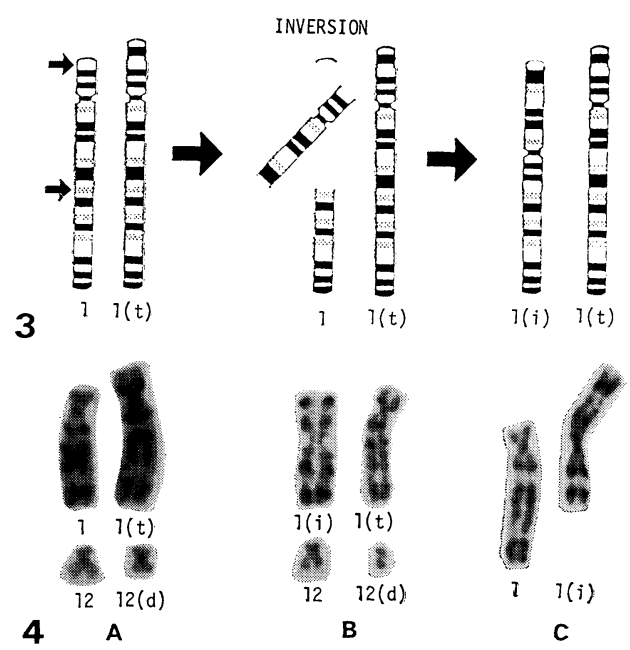

Figs. 3-4. 3: Scheme of inversion of pair no. 1 chromosome found in the mosaic rat. Small arrows indicate breakage points. 1(t) and 1(i) show translocation and inversion pair no. 1. 4: G-banding pairs 1 and 12 with translocation, inversion and deletion. A, normal and translocation pair no. 1 and normal and deletion pair no. 12. B, inversion and translocation pair no. 1 and normal and deletion pair no. 2. C, normal and inversion pair no. 1, showing the correspondance of bands between them. 12 (d) denotes pair no. 12 with deletion. Refer to Fig. 3 for $1(t)$ and $1(i)$.

2) Frequencies of two type cells in the mosaic rat. The chromosome mosaic of the present rat was initially found in cells from tail culture. The karyotype was examined in 97 cells. The frequency of cells with the translocation and normal partner $(t /+)$ and the translocation and inversion partner $(\mathrm{t} / \mathrm{i})$ was nearly identical, showing 49 cells for the former and 48 cells for the latter. The karyotype of 29 cells derived from the ear tissue culture was analysed, and the two type cells $(t /+$ and $t / i)$ were also found to occur with the same frequency $(15, \mathrm{t} /+: 14, \mathrm{t} / \mathrm{i})$. Further, 100 cells were directly observed in bone marrow of the mosaic rat, and it was shown that the $t / i$ cells were considerably higher in frequency than the $t /+$ cells, the former cells being nearly two times the latter cells. In a total of 226 cells, the 
$\mathrm{t} / \mathrm{i}$ cells showed about $56 \%$, while the $\mathrm{t} / \mathrm{+}$ cells were at about $44 \%$ (Table I).

Table I. Frequencies of somatic cells with $t /+$ and $t / i$ chromosome no. 1 in the mosaic rat

\begin{tabular}{ccccr}
\hline \multirow{2}{*}{ Cell types* } & \multicolumn{3}{c}{ Tissues examined** } & \multirow{2}{*}{ Total (\%) } \\
\cline { 2 - 4 } & Tail & Ear & Bone marrow & \\
\hline $\mathrm{t} / \mathrm{t}$ & 49 & 15 & 35 & $99(44.0)$ \\
$\mathrm{t} / \mathrm{i}$ & 48 & 14 & 65 & $127(56.0)$ \\
\hline Total & 97 & 29 & 100 & $226(100.0)$ \\
\hline
\end{tabular}

* $\mathrm{t}$ and $\mathrm{i}$ mean the translocation and inversion pair no. 1, respectively. ** In tail and ear primary cultured cells are used.

3) Transmission of the mosaic karyotype to the offspring. In the mating between the mosaic female rat and the normal Long-Evans strain rat, 6 offspring (4우:2\}) were obtained in 3 litters. If the female germ cells would be mosaic as occurred in the somatic cells, three types of ova carrying the normal, the translocation and the inversion chromosome no. 1 can be expected with the segregation at $1: 2: 1$, and also the offspring can be expected to be the normal homologous pair no. $1(+/+)$, the normal and translocation heterologous pair no. $1(+/ t)$, and the normal and inversion heterologous pair no. 1 $(+/ i)$ at the same segregation ratio as that of the female gametes. In six offspring here obtained, the above three cell types showed a segregation at the expected ratio (Fig. 5 and Table II), though the

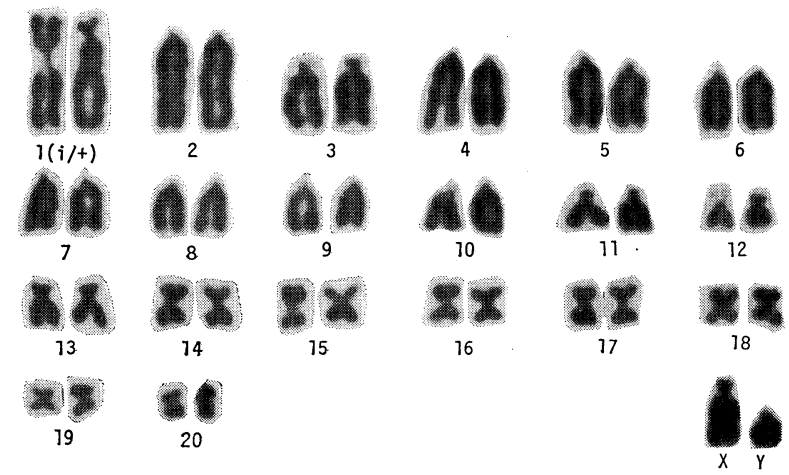

Fig. 5. Karyotype with inversion and normal pair no. $1(\mathrm{i} /+)$ which occurred in the offspring from mosaic rat.

number of offspring was small. The above findings strongly suggest that the chromosome mosaicism of the female rat occurs in both somatic and germinal cells, and that two type cells $(+/ t$ and $i / t)$ are 
present nearly equally in the female gonad.

Discussion. Chromosome mosaics have often been reported in the sex chromosome of human materials. Since the first report of Ford et al. (1959) regarding 46,XX/47,XXY mosaicism, a number of cases have been recorded in man (cf. Makino 1975). Sex chromosome mosaicism was also found in the other animals. Information on the autosomal mosaicism and their transmission to the offspring has not been presented so far in the rat.

Table II. Segregation of $F_{1}$ off spring with $+/+, t /+$ and $i /+$ pair no. 1, born from mosaic female $\times$ normal male

\begin{tabular}{|c|c|c|c|c|}
\hline \multirow{2}{*}{ parents* } & \multicolumn{4}{|c|}{$F_{1}$ offspring** } \\
\hline & $+1+$ & $t /+$ & $\mathrm{i} /+$ & Total \\
\hline $\begin{array}{l}\operatorname{Mosaic}(\text { 우 }) \times \operatorname{Normal}(\hat{\mathrm{O}}) \\
(\mathrm{t} / \mathrm{t}, \mathrm{t} / \mathrm{i})\end{array}$ & $\begin{array}{c}1 \\
(1.5)\end{array}$ & $\begin{array}{c}3 \\
(3.0)\end{array}$ & $\begin{array}{c}2 \\
(1.5)\end{array}$ & $\begin{array}{c}6 \\
(6.0)\end{array}$ \\
\hline
\end{tabular}

* Refer to Table I for $\mathrm{t}$ and $\mathrm{i}$. ** Expected numbers of $\mathrm{F}_{1}$ segregation are denoted in parentheses.

The chromosome mosaicism seems to deal with two events in its cause: One is chromosomal errors occurring in the course of embryonic development after fertilization, and the other is resulted from the fertilization with supernumerary spermatozoa and/or the reunion with the polar body. The mosaicism of the present case seems to deal with the first mechanism described above. In this mosaic rat two type cells were present at nearly the same ratio. This means that the chromosome inversion of pair no. 1 could have occurred in the very early embryonic stage, probably after the first cleavage. The frequency of two type cells was nearly identical in both tail and ear tissues, while in the bone marrow the frequency of the $t / i$ cells was considerably higher than that of the $t /+$ cells. Very probably the $t / i$ cells would be predominantly selected in the course of the bone marrow development. From the investigation of the segregation in the offspring the suggestion may be possible that the ovary contains the two type cells at an equal frequency.

It has been shown that the karyotype of the black rat (Rattus rattus) is very mutable by showing karyologically rather polymorphism and geographic variants, whereas the Norway rat is karyotypically rather stable and less mutable (Yosida 1980b). Except for a small inversion of pair no. 3 (Yosida and Amano 1965), no remarkable alteration has been referred to in the literature. It is interesting to see in the Lewis-strain rat two drustic alterations involving the largest pair no. 1. It is difficult to inquire into its casual procedure. We know that pair no. 1 of the Norway rat is generally stable, while 
in contrast it is highly polymorphic in the black rat (see Yosida $1980 \mathrm{~b}$ ). It seems very probable that the translocation should have accidentally occurred in a Lewis rat, and the heteromorphic pair no. 1 thus formed might have affected the normal chromosome partner to induce the pericentric inversion in the course of embryogenesis resulting in the establishment of mosaic rat with two cell types.

Summary. A female rat with chromosome mosaic consisting of two cell types $(+/ t)$ and $(i / t)$ was found in offspring from the Lewis strain rat with the $1 / 12$ translocation. Two cell types $(+/ t$ and $i / t)$ occurred at nearly equal frequency in the tail and ear tissues, though the former was less than the latter in marrow cells. The chromosomes with translocation and inversion was independently transmitted to the offspring at the ratio as expected.

Acknowledgments. The author is grateful to Emeritus Professor Sajiro Makino, M. J. A., for his critical reading of this manuscript with keen interest. He also indebted to Mrs. Yuriko Ochiai-Hirai, Miss Etsuko Hamada and Mr. Masabumi Funatsu for their technical assistances in preparation of materials.

\section{References}

Ford, C. E., Polani, P. E., Bringgs, J. H., and Biship, P. M. F. (1959) : Nature, 183, 1030-1032.

Makino, S. (1975) : Human Chromsomes. Igaku-Shoin, Ltd., Tokyo.

Yosida, T. H. (1980a) : Proc. Japan Acad., 56B, 268-272.

- (1980b): Cytogenetics of the Black Rat-Karyotype Evolution and Species Differentiation. Univ. Tokyo Press, Tokyo.

Yosida, T. H., and Amano, K. (1965) : Chromosoma (Berl.), 16, 658-667. 